\title{
ANALISIS DAN PERANCANGAN APLIKASI BERBASIS WEB E-PROCUREMENT DI PT PILLAR UTAMA CONTRINDO
}

\author{
Sartika Kurniali; Rudy; Alex Chandra Wijoyo; Ferdianto; Wendy \\ Information Systems Department, School of Information Systems, Binus University \\ Jl. K.H. Syahdan No. 9, Palmerah, Jakarta Barat 11480 \\ SartikaKurniali@binus.edu; rudy@binus.edu
}

\begin{abstract}
The aim of this research is to analyze the current business process at the procurement department at PT Pillar Utama Contrindo as well as develop a web based e-procurement application prototype to support procurement process at the company. Interview, survey, as well as analysis and design to develop the prototype are used in the research. The research results in an e-procurement application prototype built to minimize errors on related document filling, help the company to get best price on their supply, and increase control. It can be concluded from the research that the protoype can be implemented to be a tool for the users to decide the best supplier, obtain the best price, and increase control in buying process at PT Pillar Utama Contrindo.
\end{abstract}

Kata kunci: procurement, e-procurement, prototype, analyze and design

\begin{abstract}
ABSTRAK
Tujuan penelitian ini menganalisis proses bisnis yang berjalan pada bagian pengadaan lalu mengembangkan prototype aplikasi e-procurement berbasis web untuk mendukung proses pengadaan di PT Pillar Utama Contrindo. Metodologi yang digunakan adalah dengan wawancara, survei, analisis dan perancangan dalam menyusun prototype aplikasi e-procurement pada PT Pillar Utama Contrindo. Hasil yang dicapai berupa prototype aplikasi e-procurement yang diharapkan dapat meminimalisasi kesalahan-kesalahan dalam pengisian dokumen terkait, membantu perusahaan untuk mendapatkan barang yang ingin dibeli dengan harga terbaik, dan mampu meningkatkan kontrol dalam unit proses bisnis pengadaan barang. Kesimpulan penelitian ini, yaitu protoype e-procurement dapat diimplementasikan sehingga menjadi tool bagi user untuk melakukan penentuan supplier, dan mendapat harga terbaik, selain itu meningkatkan kontrol bagi unit pembelian di dalam PT Pillar Utama Contrindo, dan mengatasi segala masalah-masalah yang terjadi di dalam proses pengadaan di dalam PT Pillar Utama Contrindo.
\end{abstract}

Kata kunci: procurement, e-procurement, prototype, analisis dan perancangan 


\section{PENDAHULUAN}

Kompleksitas seringkali terjadi dari setiap proses bisnis dan seringkali masalah persediaan menjadi hal yang begitu berpengaruh terhadap proses bisnis secara keseluruhan karena penerapan atau implementasi procurement yang menggunakan metode manual tidak mampu mendukung proses bisnis agar lebih efisien dan efektif bagi perusahaan. Untuk mengatasi hal ini, beberapa perusahaan telah mengadopsi otomatisasi e-procurement pada semua tahap dari proses suplai untuk memaksimalkan keuntungan. E-procurement menjadi salah satu solusi yang terbaik untuk menyelesaikan masalah yang terjadi di dalam proses persediaan tersebut.

E-procurement adalah teknologi yang dirancang untuk memfasilitasi pengadaan barang melalui internet, manajemen seluruh aktivitas pengadaan secara elektronik. Aspek-aspek fungsi pengadaan yang didukung oleh bermacam-macam bentuk komunikasi secara elektronik (Davila, et al., 2002). Menurut Kalakota, Ravi dan Robinson (2001), e-procurement merupakan proses pengadaan barang atau lelang dengan memanfaatkan teknologi informasi dalam bentuk website. Efisiensi eprocurement mencakup biaya yang rendah, mempercepat waktu dalam proses procurement, mengontrol proses pembelian dengan lebih baik, menyajikan laporan informasi, dan pengintegrasian fungsi-fungsi procurement sebagai kunci pada sistem back-office. Sedangkan efektivitas eprocurement yaitu meningkatkan kontrol pada rantai nilai, pengelolaan data penting yang baik, dan meningkatkan kualitas pengambilan keputusan dalam proses pembelian pada organisasi.

PT Pillar Utama Contrindo merupakan perusahaan yang bergerak di bidang manufaktur dan penjualan berupa perakitan alat atau perlengkapan elevator, escalator serta jasa perawatan. PT Pillar Utama Contrindo didirikan pada Agustus tahun 1995. Pada awal berdiri, PT Pillar Utama Contrindo hanya melayani jasa perawatan escalator dan elevator. Pada tahun 1995 sampai 1998, PT Pillar Utama Contrindo menjadi agen yang menjual dan menginstalasi escalator dan elevator merek Korea untuk daerah Bandung dan sekitarnya. Kemudian pada tahun 2002, PT Pillar Utama Contrindo mulai memproduksi elevator dan produk pertama PT Pillar Utama Contrindo diinstalasi pada Universal School Project, Jakarta. Saat ini PT Pillar Utama Contrindo berkantor pusat Bandung dan mempunyai cabang di Jakarta (Kokan Pertama Kelapa Gading Blok B 11, Jalan Boulevard Bukit Gading Raya) dan Surabaya.

PT Pillar Utama Contrindo mempunyai tujuan yaitu dengan mengkombinasikan service yang serius dan kepercayaan baik dari Customer. Untuk mendukung tujuan PT Pillar Utama Contrindo, diperlukan aktivitas-aktivitas proses bisnis yaitu proses pengadaan pada khususnya yang memiliki peranan yang sangat penting atau core dari PT Pillar Utama Contrindo. Dengan proses pengadaan barang yang efisien dan transparan, secara otomatis akan mengurangi beban dan mempercepat proses pengadaan sehingga tingkat produktivitas perusahaan lebih tinggi dan mencapai keuntungan yang optimal.

Saat ini PT Pillar Utama Contrindo melakukan pengadaan barang secara manual. Karena kebutuhan yang semakin mendesak, dan untuk mendukung efisiensi perusahaan agar dapat lebih berkembang, maka penggunaan e-procurement sebagai solusi atau alternatif dari proses pengadaan secara konvensional. E-procurement dapat diterapkan agar proses pengadaan barang dapat dilakukan lebih baik, lebih efisien, dan lebih transparant.

Menurut Davila et al (2002), langkah-langkah dari masing-masing proses yang dideskripsikan dengan detail, yaitu: (1) jadwal pengiriman, di mana project management perusahaan membutuhkan produk atau jasa yang disiapkan dalam list produk, atau jasa yang dibutuhkan untuk implementasi project; (2) memilih supplier, berdasarkan dengan list dari produk atau jasa, investor memilih supplier yang tersedia, ide kunci dari skenario inovatif pengembangan dan efektifitas dan rasional supplier di 
mana terdapat partisipan dalam jumlah besar supplier. Hal tersebut akan dikomparasi dengan apa yang dipelajari. Langkah ini dimasukkan kedalam pemesanan yang ditambahkan pengetahuan teknologi ke dalam proses ini. Pencarian dalam database internal berupa white list dan black list di dalam database perusahaan. White list adalah data yang disimpan perusahaan dalam bentuk list, yang direkomendasikan karena kepercayaan terhadap perusahaan supplier tersebut (Supplier terpercaya), yang berisi informasi berharga dari pekerjaan sebelumnya, dan informasi dari aktivitas supplier, tipe produk, dan lain-lain. Sedangkan Black list adalah data yang disimpan perusahaan dalam bentuk list, yang tidak direkomendasikan karena kepercayaan perusahaan terhadap perusahaan supplier tersebut, dari informasi aktivititas atau pekerjaan sebelumnya, dan lain-lain. Pencarian eksternal dapat dilakukan dengan menunggu supplier yang masuk. Selanjutnya dilakukan penyiapan list final dari supplier berpotensi; (3) persiapan, dan mengirim permintaan quotation berisi list, produk atau jasa, syarat pembayaran dan pengiriman, deadline quotation, dan informasi yang terindikasi. Setelah mengirim, maka menunggu jawaban.; (4) analisis quotation, dan pemilihan supplier, jika penawaran telah didapatkan, maka dilakukan analisis, dan keputusan, dari keputusan akhir supplier untuk memprosesnya, yang dipecah menjadi tugas-tugas kecil, seperti: mendapatkan penawaran dan pemilihan berdasarkan rating atau ranking; (5) negosiasi dan order, setelah itu, dilakukan negosiasi dengan supplier yang terpilih, dan penempatan order atau pemesanan, order atau pemesanan merepresentasikan semua kondisi (biaya, jumlah, harga, pembayaran, pengiriman, dan kondisi lainnya); (5) penyampaian keseluruhan dari pengiriman, sebelum bill dikirim ke kantor, atau gudang, harus dicek, yang dilakukan adalah sesuai rencana (mengecek sertifikasi kualitas, kuantitas, dan waktu pengiriman).

\section{METODE}

Metodologi yang digunakan adalah dengan wawancara, survei, serta analisis dan perancangan menggunakan framework PIECES, class diagram, dan use case.

\section{HASIL DAN PEMBAHASAN}

\section{Identifikasi Masalah}

Dalam menganalisis dan mengidentifikasi masalah, digunakan sebuah framework (Tabel 1) yang mendefinisikan masalah yang terjadi di dalam PT Pillar Utama Contrindo.

Tabel 1

Framework PIECES

\begin{tabular}{llll}
\hline Performance & \multicolumn{1}{c}{ Problem } & Opportunity & \multicolumn{1}{c}{ Directive } \\
& (1). Adanya faktor & (1). Menerapkan & (1). Pada sistem e-procurement yang \\
keterlambatan dalam & diusulkan, proses pemberian \\
pemberian dokumen & standarisasi & dalam & dokumen dari satu bagian ke bagian \\
dari satu bagian ke & pemrosesan & lainnya akan lebih cepat karena \\
bagian lainnya. & suatu dokumen. & sistem e-procurement dapat \\
& (2). Beberapa staff & & melakukan pemrosesan lebih cepat \\
melakukan kesalahan & & dan sistem e-procurement dapat \\
dalam pencatatan & & diakses dari mana saja melalui \\
dokumen-dokumen & & internet. \\
dan form-form dalam & & (2). Dengan Sistem e-procurement, \\
proses pengadaan & & pengisian form-form dilakukan oleh \\
\hline
\end{tabular}


supplier, dan data-data akan dapat digunakan kembali sehingga kesalahan karena pengisian formform dapat diminimalisasi.

\begin{tabular}{|c|c|c|c|}
\hline Information & $\begin{array}{l}\text { (1). Bagian procurement } \\
\text { kesulitan penentuan } \\
\text { supplier yang tepat } \\
\text { dalam proses } \\
\text { pengadaan barang. } \\
\text { (2). Bagian Procurement } \\
\text { kesulitan dalam } \\
\text { pembuatan laporan } \\
\text { pembelian. }\end{array}$ & $\begin{array}{l}\text { (1). Menetapkan } \\
\text { standarisasi } \\
\text { untuk proses } \\
\text { pemilihan } \\
\text { supplier. }\end{array}$ & $\begin{array}{l}\text { (1). Pada sistem e-Procurement yang } \\
\text { diusulkan, terdapat fitur untuk } \\
\text { melihat kinerja supplier dalam } \\
\text { bentuk pengambaran grafik untuk. } \\
\text { mempermudah penentuan supplier } \\
\text { (2). Sistem e-procurement yang } \\
\text { diusulkan mampu menghasilkan } \\
\text { laporan pembelian. }\end{array}$ \\
\hline \multicolumn{4}{|l|}{ Economics } \\
\hline Control & $\begin{array}{lr}\text { (1). Beberapa Staff dan } \\
\text { Head Of Procurement } \\
\text { Kesulitan r dalam } \\
\text { melakukan tracking } \\
\text { ataurantaun pemantauan } \\
\text { proses pengadaan. }\end{array}$ & & $\begin{array}{l}\text { (1). Pada Sistem E-Procurement yang } \\
\text { diusulkan, terdapat fitur tracking } \\
\text { untuk memantau proses pengadaan. }\end{array}$ \\
\hline \multicolumn{4}{|l|}{ Efficiency } \\
\hline Service & & & \\
\hline
\end{tabular}

Setelah melakukan analisis dan penelitian terhadap sistem yang sedang berjalan saat ini, ditemukan masalah-masalah yang dihadapi oleh PT Pillar Contrindo, seperti: kesulitan penentuan supplier yang tepat dalam proses pengadaan barang, kesulitan dalam melakukan tracking atau pemantauan proses pengadaan, kesalahan dalam pencatatan dokumen-dokumen dan form-form dalam proses pengadaan barang, contohnya dalam pengisian identitias supplier, no telp supplier, no rekening, sehingga menghambat proses pengadaan, faktor keterlambatan dalam pemberian dokumen dari satu bagian ke bagian lainnya sehingga menghambat proses pembelian, serta kesulitan dalam pembuatan laporan pembelian.

\section{Usulan pemecahan masalah}

Dari berbagai masalah yang timbul yang telah dianalisis, dan kebutuhan informasi yang sedang berjalan, maka diusulkan pemecahan masalah untuk mengatasi masalah yang ada pada PT Pillar Utama Contrindo yaitu: (1) sistem yang dibuat adalah sistem e-procurement atau proses pengadaan melalui internet; (2) pada sistem e-procurement yang diusulkan, terdapat fitur untuk melihat kinerja supplier selama bekerja sama dengan perusahaan dalam bentuk pengambaran grafik dan memberikan informasi tentang penawaran harga yang diberikan oleh supplier untuk mempermudah penentuan supplier saat proses pengadaan barang; (3) pada sistem e-procurement yang diusulkan, terdapat fitur untuk melakukan tracking/pelacakkan untuk memantau proses pengadaan; (4) dengan sistem e-procurement yang diusulkan, pengisian form-form dilakukan oleh supplier, dan datadata akan dapat digunakan kembali sehingga kesalahan karena pengisian form-form dapat diminimalisasi; (5) pada sistem e-procurement yang diusulkan, proses pemberian dokumen dari satu bagian ke bagian lainnya akan lebih cepat karena sistem e-procurement dapat melakukan pemrosesan lebih cepat dan sistem e-procurement dapat diakses dari mana saja melalui internet; (6) sistem $e$ procurement yang diusulkan mampu menghasilkan laporan pembelian.

\section{Perancangan}

Perancangan sistem informasi e-procurement pada PT Pillar Utama Contrindo ditampilkan dalam diagram-diagram berikut (Gambar 2 dan 3). 


\section{Rancangan Layar}

Rancangan Layar sistem e-procurement pada PT Pillar Utama Contrindo ditampilkan pada Gambar 4 dan 5.

\section{Tampilan Layar} dan 7).

Tampilan layar website e-procurement PT Pillar Utama Contrindo sebagai berikut (Gambar 6

\section{PENUTUP}

Setelah membuat analisis dan perancangan e-procurement pada PT Pillar Utama Contrindo, maka dapat diambil kesimpulan bahwa Prototype E-procurement yang dirancang dapat menjadi tool bagi user untuk melakukan penentuan supplier, dalam proses pemilihan penentuan pemenang, Fasilitas Tracking, menjadi fasilitas yang informatif, karena fasilitas tracking dapat menjembatani antara supplier, dengan PT Pillar Utama Contrindo dalam proses transaksi.

Sebagai saran, sebelum bisa menggunakan aplikasi, user yang mendaftar sebaiknya diverifikasi terlebih dahulu sebelum bisa mengakses fitur aplikasi. Begitu juga dengan alamat aplikasi, sebaiknya hanya diberitahukan kepada pihak-pihak yang berkepentingan untuk sebagai salah satu bentuk antisipasi keamaan aplikasi.

\section{DAFTAR PUSTAKA}

Davila, Tony, Mahendra Gupta, dan Richard Palmer. (2002). Moving Procurement Systems to the Internet: The Adoption and Use of E-Procurement Technology Models.

Kalakota, Ravi and Robinson, Marcia (2001). E-business 2.0: Roadmap For Success. Boston: Addison Wesley. 


\section{APPENDIX}

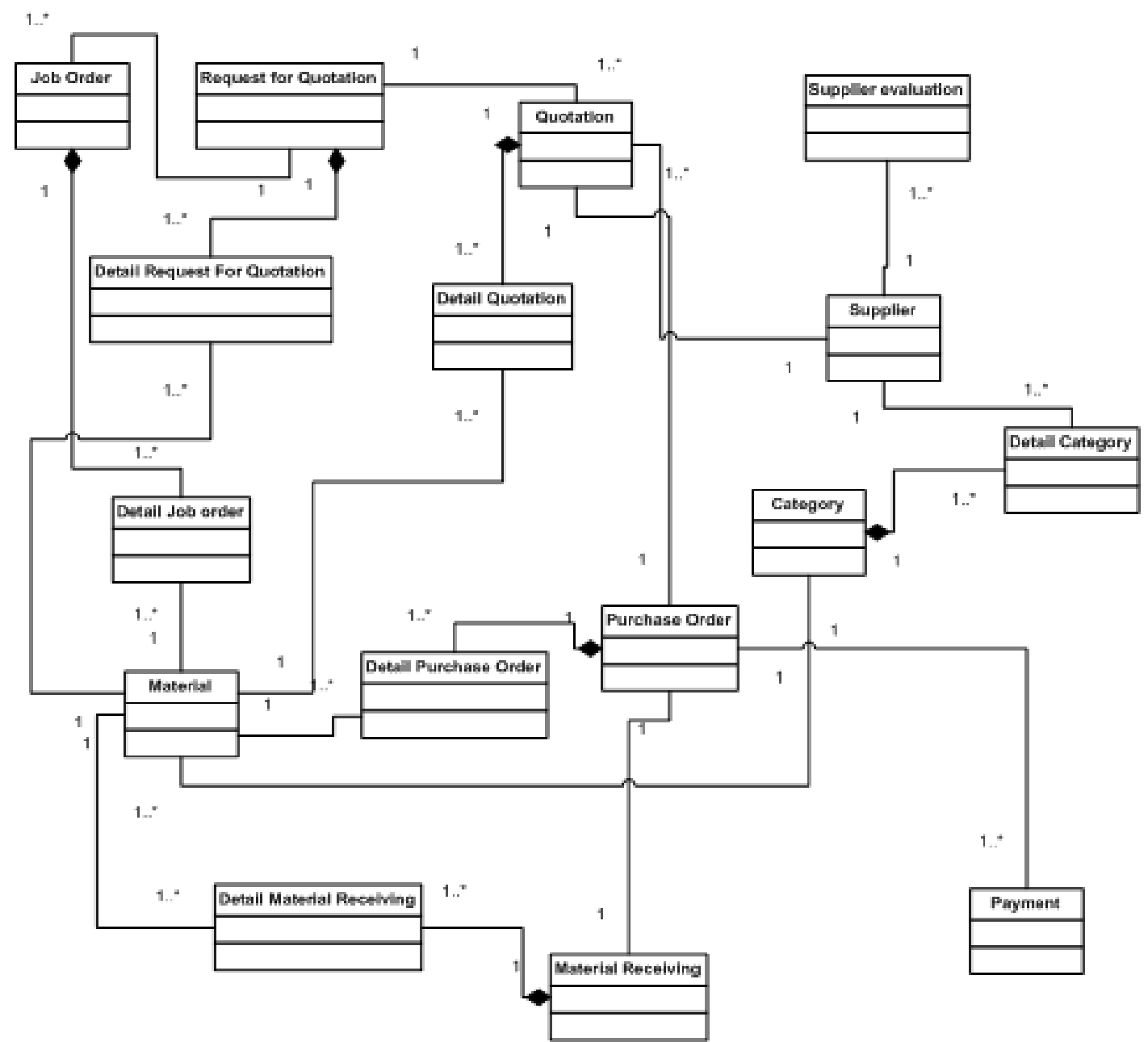

Gambar 2. Class Diagram E-Procurement PT Pillar Utama Contrindo. 


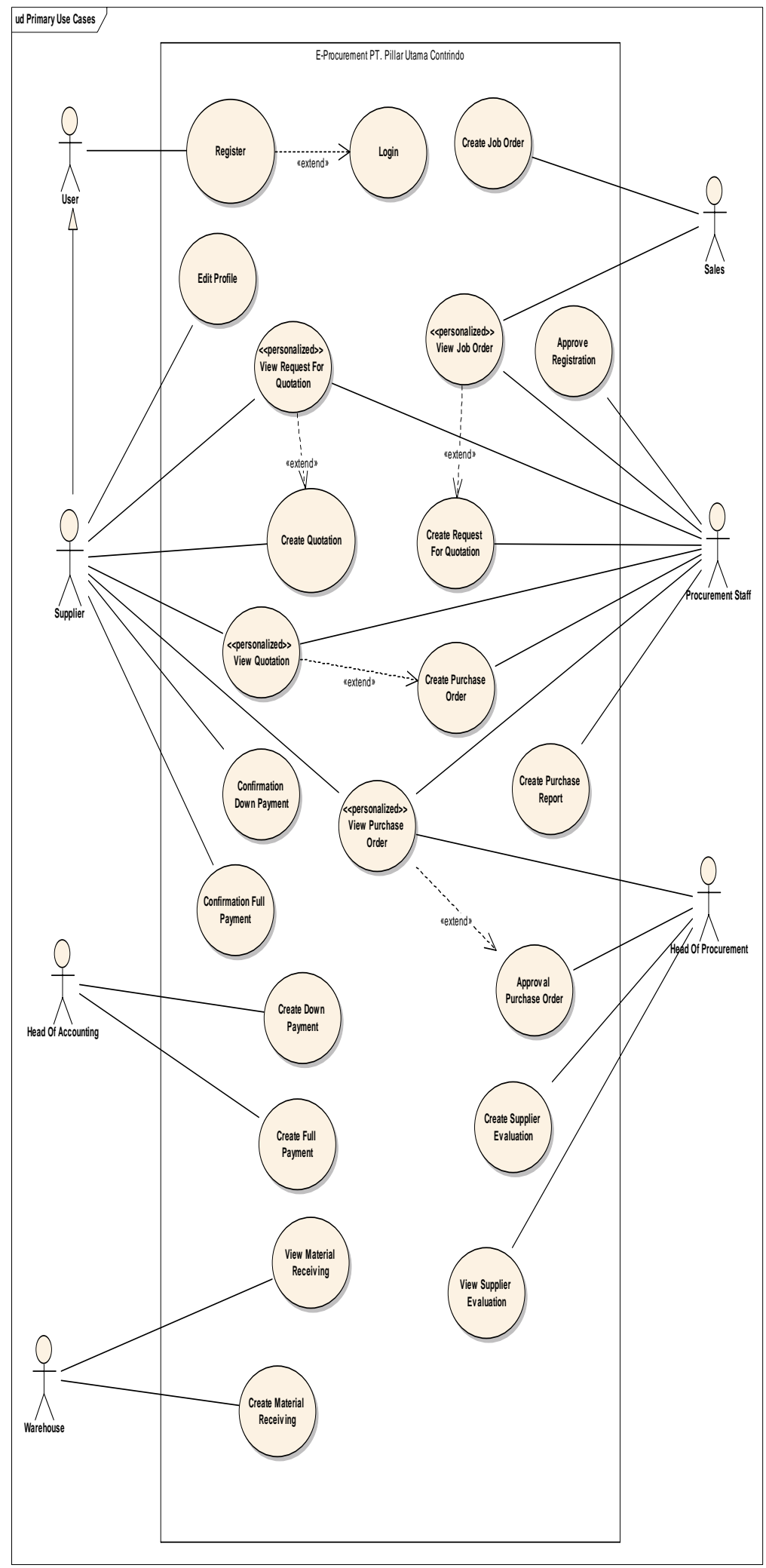

Gambar 3. Use Case E-Procurement PT Pillar Utama Contrindo. 


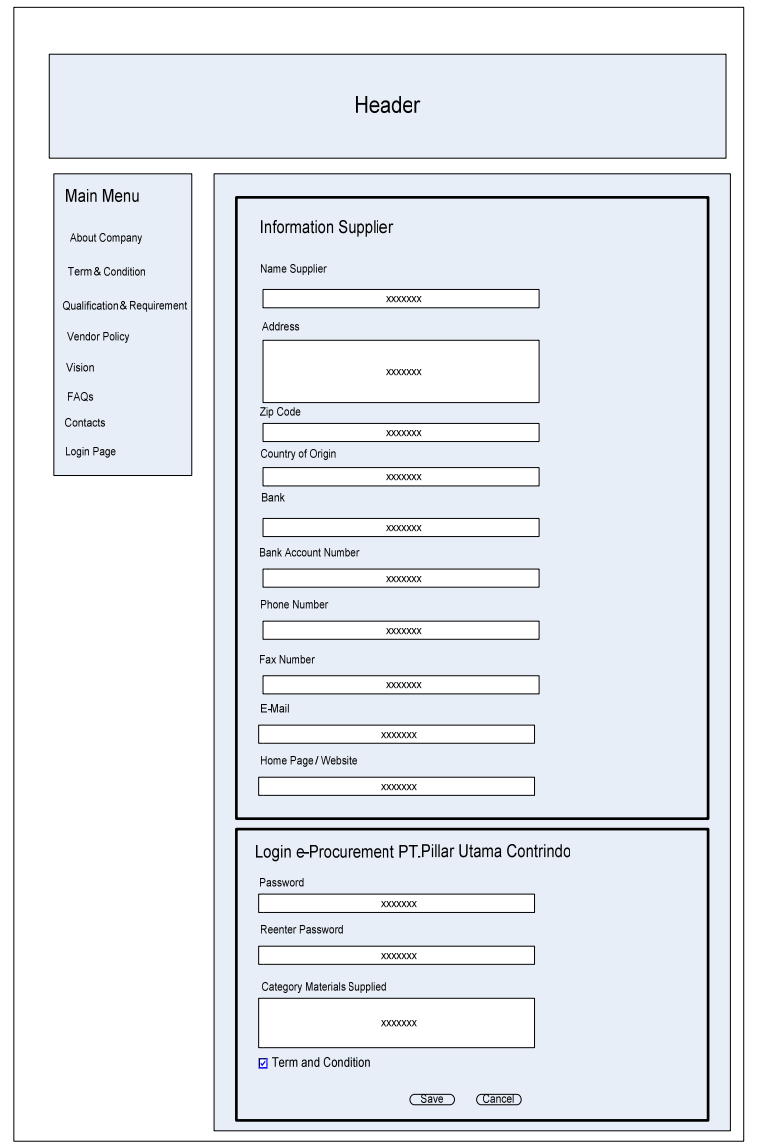

Gambar 4. Halaman registrasi informasi supplier.

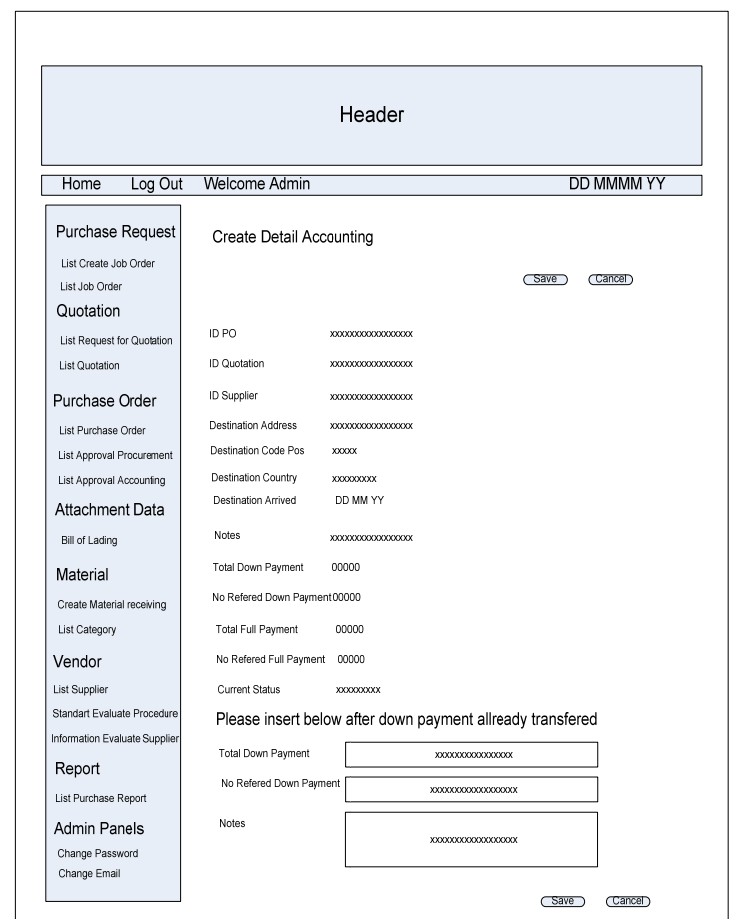

Gambar 5. Halaman pembayaran down payment. 


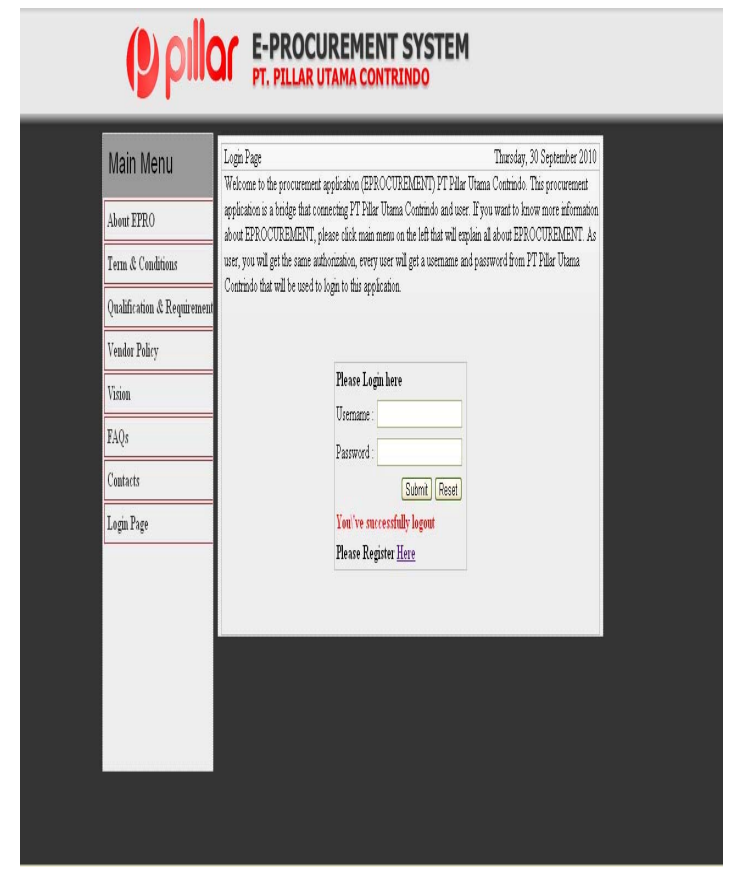

Gambar 6. Halaman login pada situs e-procurement PT Pillar Utama Contrindo.

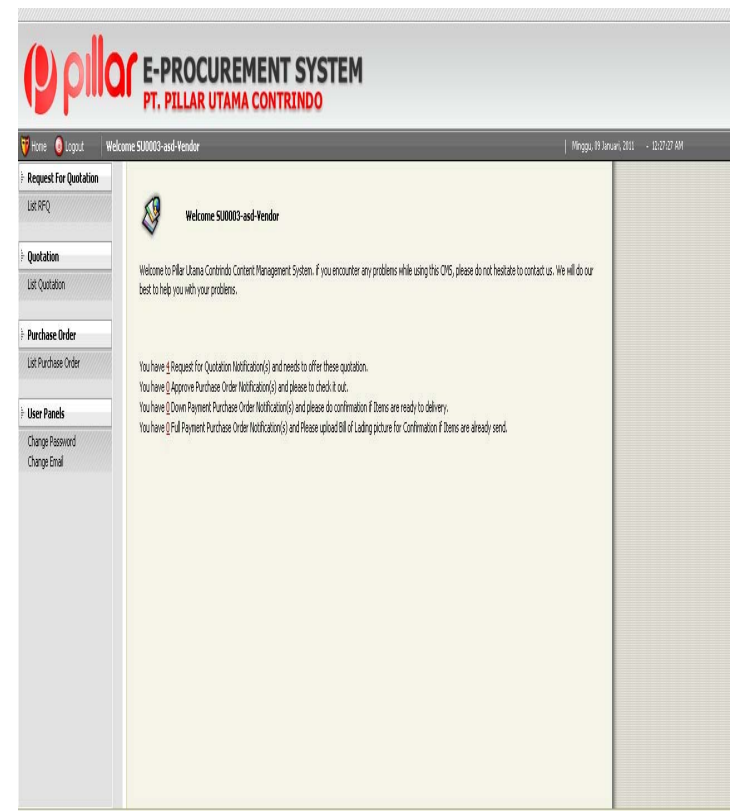

Gambar 7. Halaman utama bagi vendor atau supplier pada situs e-procurement PT Pillar Utama Contrindo. 